\title{
Cope Elimination: Elucidation of Solvent Effects from QM/MM Simulations
}

\author{
Orlando Acevedo and William L. Jorgensen* \\ Department of Chemistry, Yale University, 225 Prospect Street, \\ New Haven, Connecticut 06520-8107.
}

Supporting Material

Figure S1. For erythro - Solute-solvent energy pair distribution in water and DMSO...........S2

Figure S2. For threo - Solute-solvent energy pair distribution in THF......................S2

Figure S3. For erythro - Solute-solvent energy pair distribution in THF.....................S3

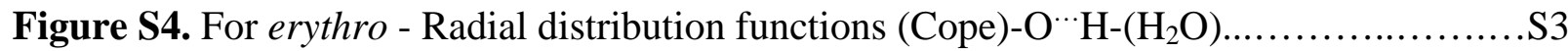

Figure S5. For erythro - Radial distribution functions (Cope)-O ${ }^{\cdots} \mathrm{CH}_{3}-(\mathrm{DMSO}) \ldots . . . . . . . . . . \mathrm{S} 4$

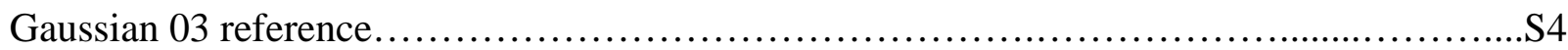




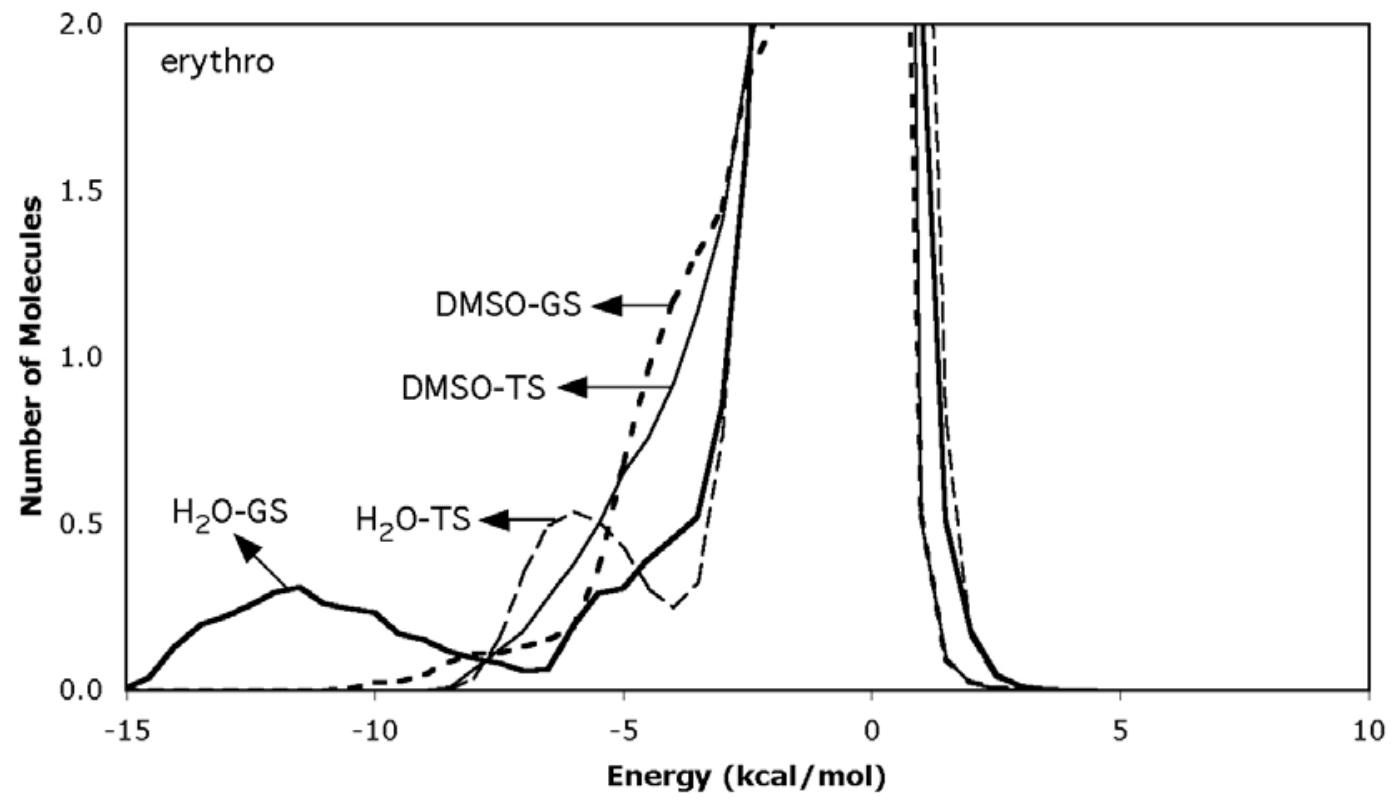

Figure S1. Solute-solvent energy pair distributions for the Cope elimination of erythro amine oxide in water and DMSO for the reactant (GS) and transition structure (TS). The ordinate records the number of solvent molecules that interact with the solutes with their interaction energy on the abscissa. Units for the ordinate are number of molecules per $\mathrm{kcal} / \mathrm{mol}$.

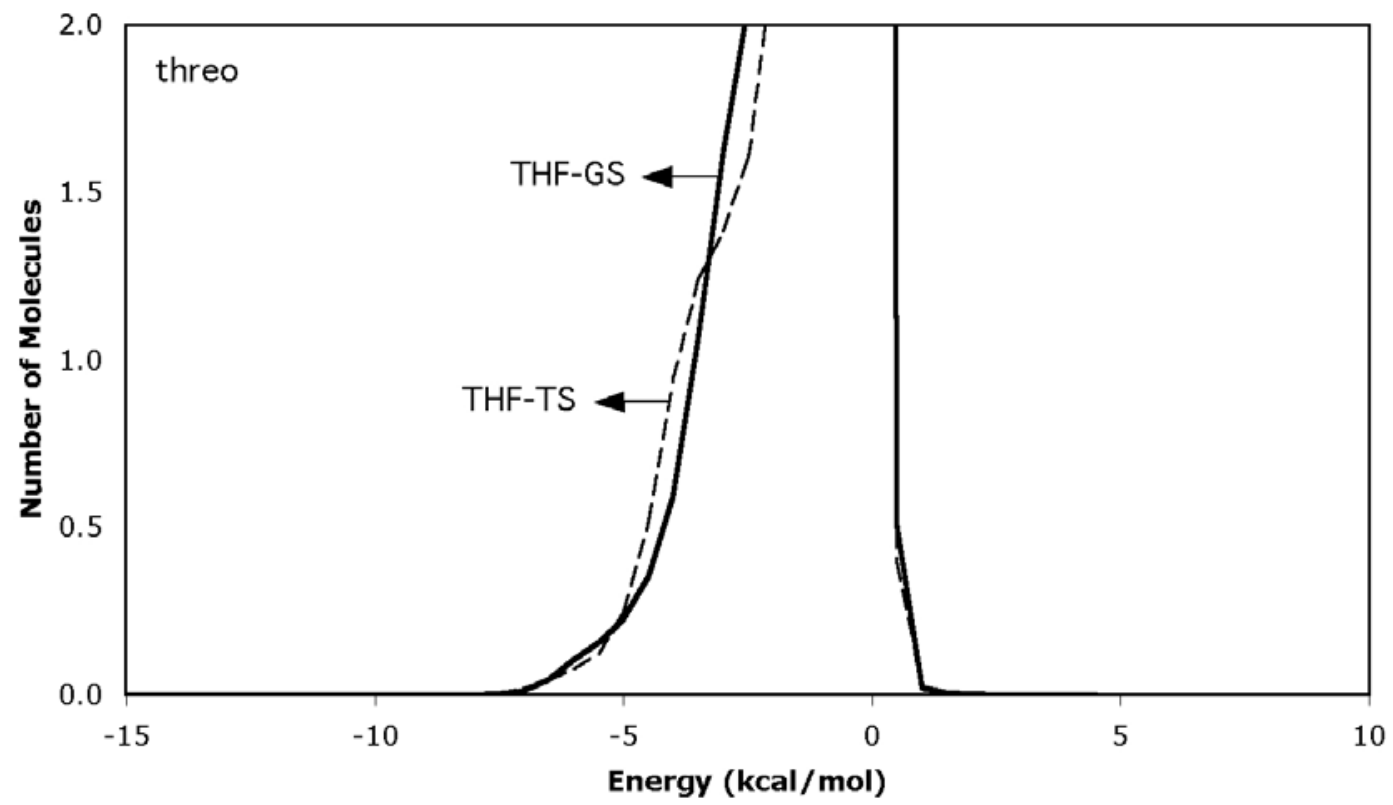

Figure S2. Solute-solvent energy pair distributions for the Cope elimination of threo amine oxide in THF for the reactant (GS) and transition structure (TS). The ordinate records the number of solvent molecules that interact with the solutes with their interaction energy on the abscissa. Units for the ordinate are number of molecules per $\mathrm{kcal} / \mathrm{mol}$. 


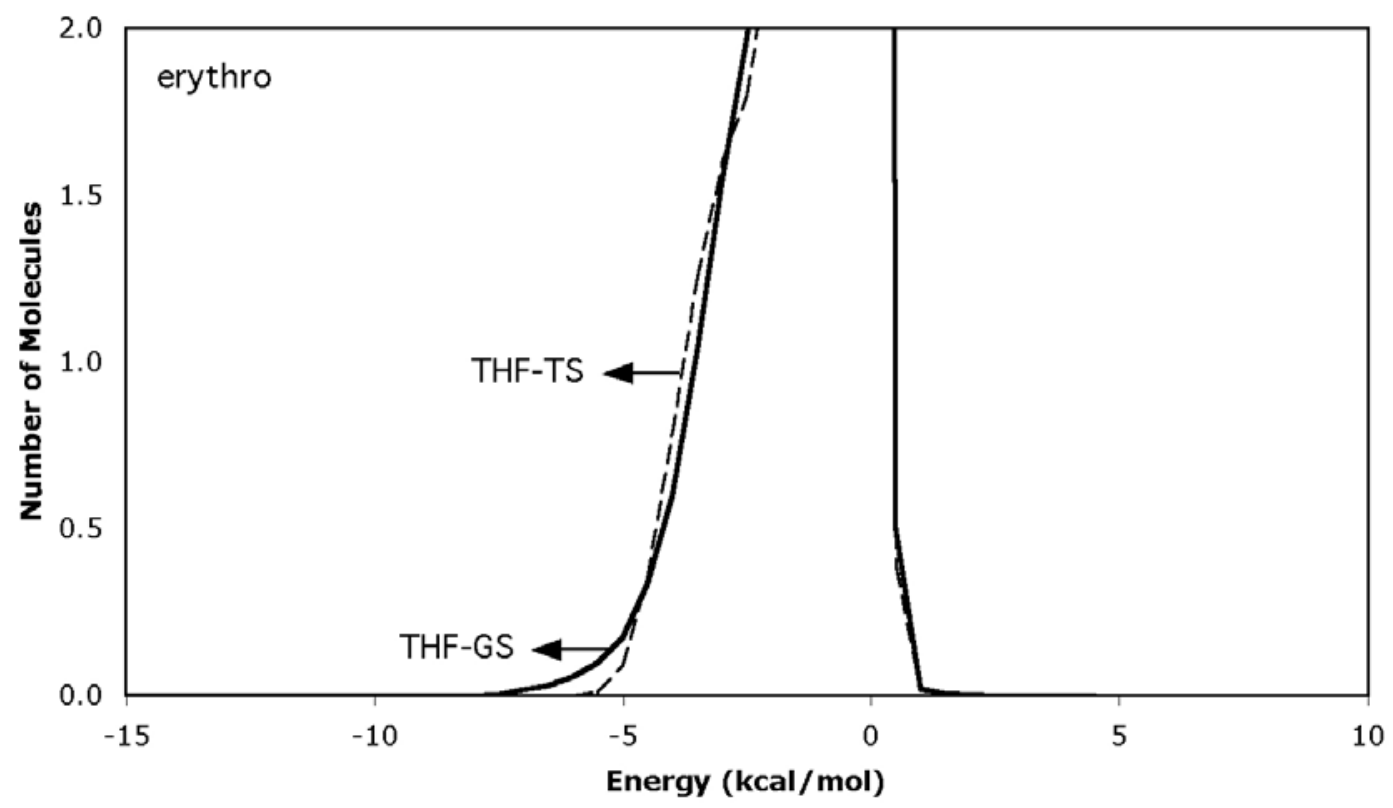

Figure S3. Solute-solvent energy pair distributions for the Cope elimination of erythro amine oxide in THF for the reactant (GS) and transition structure (TS). The ordinate records the number of solvent molecules that interact with the solutes with their interaction energy on the abscissa. Units for the ordinate are number of molecules per $\mathrm{kcal} / \mathrm{mol}$.

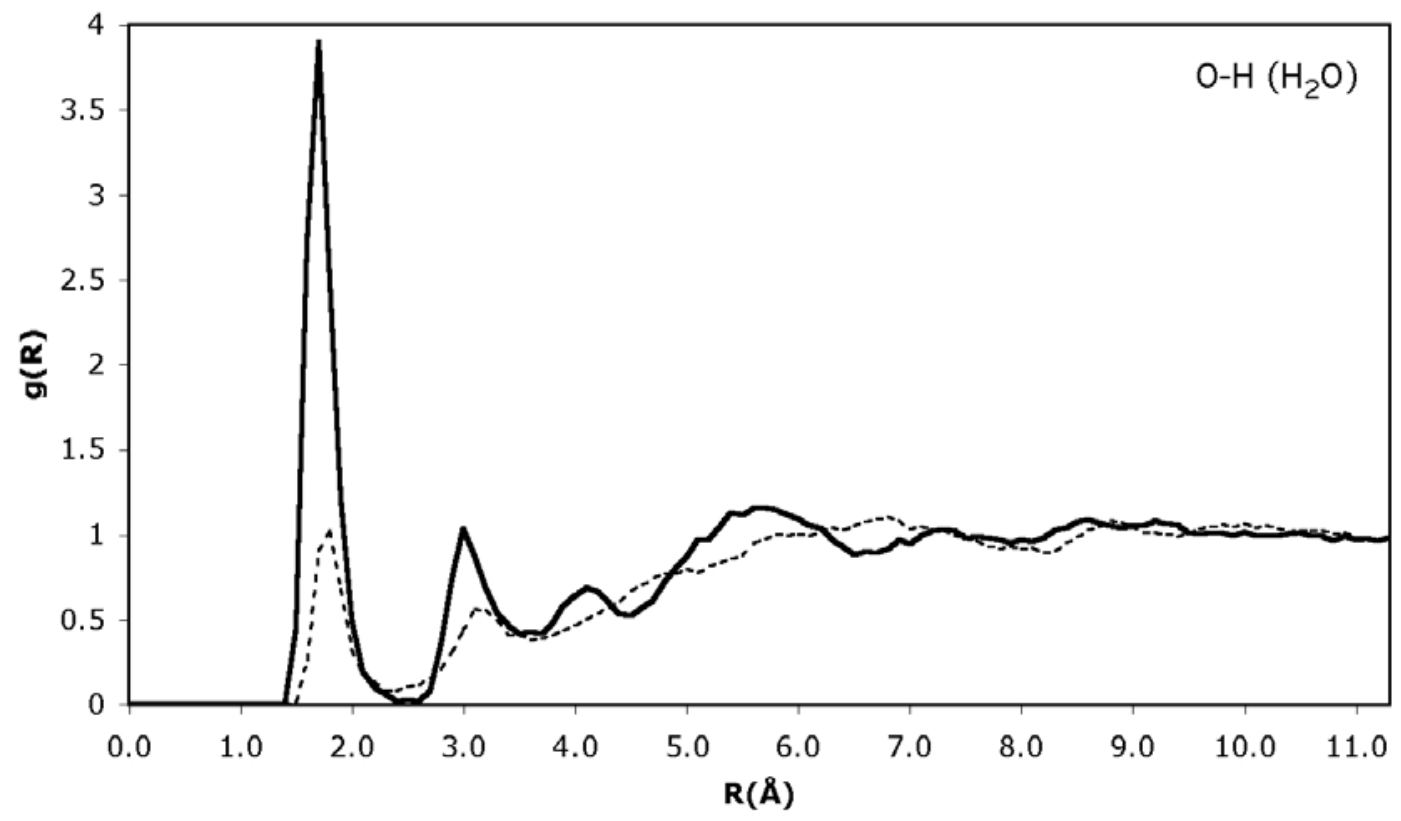

Figure S4. Computed (Cope)-O ${ }^{\cdots} \mathrm{H}-\left(\mathrm{H}_{2} \mathrm{O}\right)$ radial distribution functions for the reactant (solid curve) and transition state (dashed curve) for the reaction of erythro-N,N-dimethyl-3-phenyl-2butylamine oxide. 


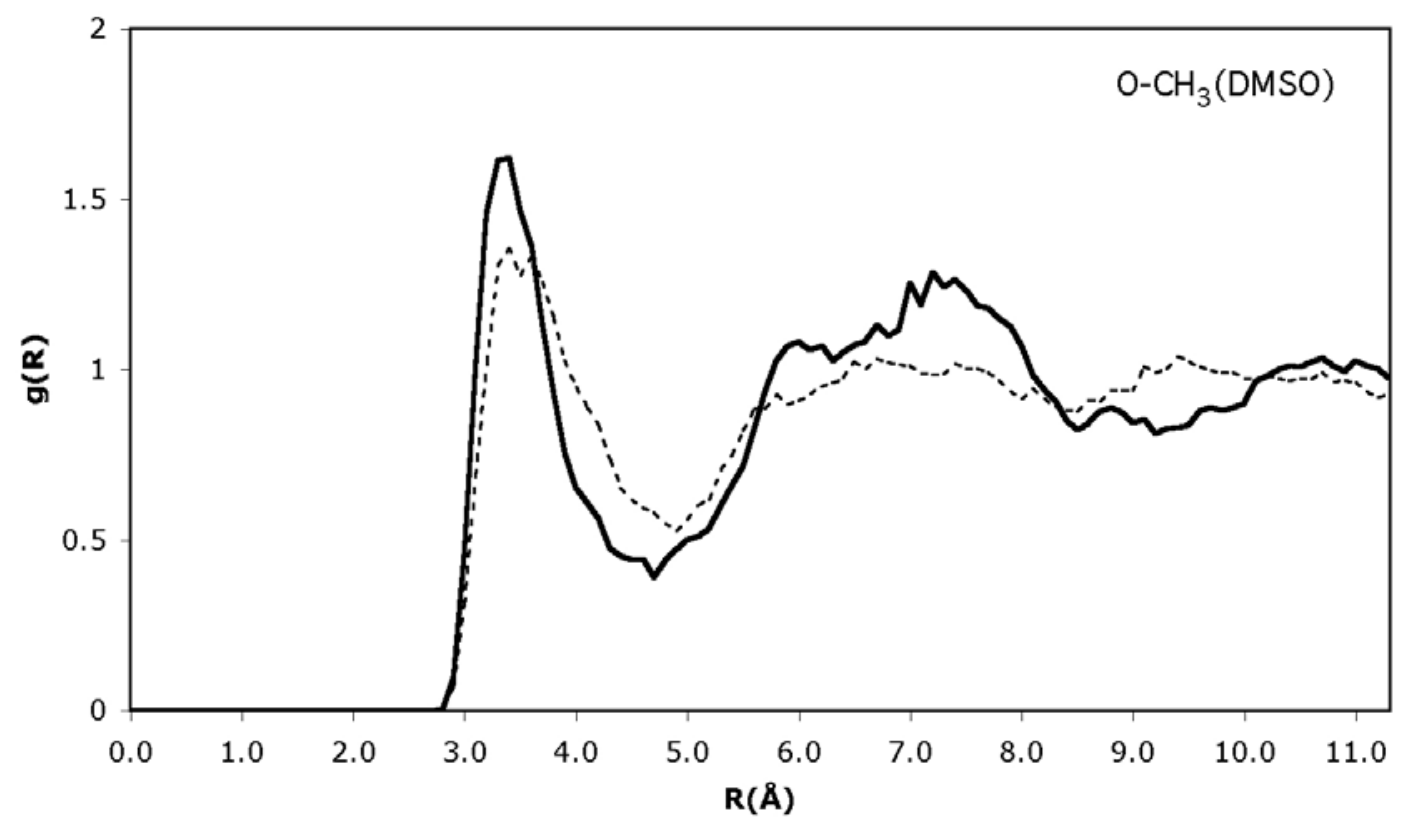

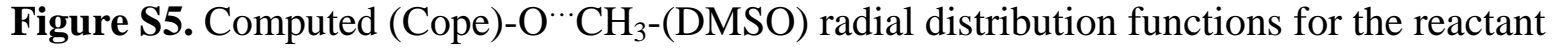
(solid curve) and transition state (dashed curve) for the reaction of erythro-N,N-dimethyl-3phenyl-2-butylamine oxide.

\section{Gaussian 03 Reference}

Gaussian 03, Revision B.03,

M. J. Frisch, G. W. Trucks, H. B. Schlegel, G. E. Scuseria,

M. A. Robb, J. R. Cheeseman, J. A. Montgomery, Jr., T. Vreven,

K. N. Kudin, J. C. Burant, J. M. Millam, S. S. Iyengar, J. Tomasi,

V. Barone, B. Mennucci, M. Cossi, G. Scalmani, N. Rega,

G. A. Petersson, H. Nakatsuji, M. Hada, M. Ehara, K. Toyota,

R. Fukuda, J. Hasegawa, M. Ishida, T. Nakajima, Y. Honda, O. Kitao,

H. Nakai, M. Klene, X. Li, J. E. Knox, H. P. Hratchian, J. B. Cross,

C. Adamo, J. Jaramillo, R. Gomperts, R. E. Stratmann, 0. Yazyev,

A. J. Austin, R. Cammi, C. Pomelli, J. W. Ochterski, P. Y. Ayala,

K. Morokuma, G. A. Voth, P. Salvador, J. J. Dannenberg,

V. G. Zakrzewski, S. Dapprich, A. D. Daniels, M. C. Strain,

0. Farkas, D. K. Malick, A. D. Rabuck, K. Raghavachari,

J. B. Foresman, J. V. Ortiz, Q. Cui, A. G. Baboul, S. Clifford,

J. Cioslowski, B. B. Stefanov, G. Liu, A. Liashenko, P. Piskorz,

I. Komaromi, R. L. Martin, D. J. Fox, T. Keith, M. A. Al-Laham,

C. Y. Peng, A. Nanayakkara, M. Challacombe, P. M. W. Gill,

B. Johnson, W. Chen, M. W. Wong, C. Gonzalez, and J. A. Pople,

Gaussian, Inc., Pittsburgh PA, 2003. 